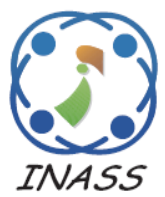

\title{
Backstepping Integral Sliding Mode Control Method for Maximum Power Point Tracking for Optimization of PV System Operation Based on High-Gain Observer
}

\author{
Rafika El Idrissi $^{1 *} \quad$ Ahmed Abbou $^{1}$ \\ Mohcine Mokhlis ${ }^{1}$ \\ ${ }^{I}$ Electrical Engineering Department, Mohammadia School of Engineers, \\ Mohammed V University in Rabat, Morocco \\ * Corresponding author's Email: rafika.elidrissi@gmail.com
}

\begin{abstract}
The temperature and radiation changes lead to obvious fluctuations in photovoltaic panels ' output power. To optimally exploit the PV system, maximum power point tracking (MPPT) is needed. Various offline and online methods for monitoring the MPP have been implemented. In this work, a maximum power point tracking (MPPT) technique was created which is primarily based on backstepping integral sliding mode controller (BISMC) design. The control scheme incorporates two parts: the first is based on an artificial neural network that provides the reference voltage, that supplies the maximum power regardless the environmental factors, which is given to the proposed BISMC control that is responsible on regulation of the duty cycle of the DC-DC boost converter's PWM applied switch (Mosfet). This strategy offers very low tracking error, and chattering improvement in tracking the MPP of a PV system when the environmental disturbances occur. The added integral action is very important in the control closed loop because it removes the steady state error. The method is compared with the ANN-sliding mode, PSO-backstepping and $\mathrm{P} \& \mathrm{O}$-backstepping controllers in order to demonstrate its efficiency. In this later, the $\mathrm{P} \& \mathrm{O}$ (perturb \& observe) and the PSO (particle swarm optimization) algorithms serve to generate reference voltage, that corresponds to the MPP, while the backstepping controller tracks this reference voltage. To reduce the PV system cost, a high-gain observer is designed, it requires only the PV output voltage sensor which enables the unmeasured PV system state variables online. This allows the minimization of the number of sensors in practical case because they have many disadvantages. The use of these sensors can lead to bulky system. Moreover, they are expensive. The simulation study is carried out under Matlab/Simulink. The results of the suggested MPPT reveal outstanding dynamic response under rapid changes of irradiation and temperature. The suggested method is more accurate and has fast convergence time about $2.2 \mathrm{~ms}$ and $1 \mathrm{~ms}$ depends on the meteorological condition changes and $98 \%$ of efficiency to track the maximum power point.
\end{abstract}

Keywords: DC/DC boost converter, Artificial neural network, Backstepping integral sliding mode controller (BISMC), MPPT, PV system, High gain observer.

\section{Introduction}

Most of our electricity requirements are met by quickly depleting non-renewable resources. The growing population and energy demand are the reason for the search for alternative solutions. Photovoltaic energy production has attracted a huge quantity of interest in this respect. However, photovoltaic energy is still regarded as costly and a primary study subject has been the cost reduction of PV systems [1, 2]. To fix the above issues, power electronics can be used to maximize PV energy. Using the MPPT controller for $\mathrm{PV}$ is crucial to the efficiency and performance of a
PV process. Consequently, in the literature many maximum power point algorithms have been created such as the perturb-and-observe (P\&O) method [3, 4] and incremental conductance (INC) method [5], which are the most widely employed approaches because they are simple and easy to implement. Nevertheless, during rapid change in climate irradiation, even under stable climate conditions. However, with reduced solar irradiation, their efficiency declines. conditions, these approaches are not successful. These often create oscillations about the MPP and are entirely dependent on solar. Compared to traditional $\mathrm{P} \& \mathrm{O}$ and IC technology, 
fuzzy logic control (FLC) method, [6], offers the best performance. However, it is due to the lack of sufficient precise operating position of the PV generator for the MPP that this technique is limited. The other disadvantage of FLC is the high implementation costs, because of the complexity of its algorithm. In addition, artificial neural network (ANN) method have a number of benefits, including stable running, fast monitoring, non-linear process sensitivity and offline learning. Several ANN-based PV MPPT approaches have therefore been introduced lately $[7,8]$. Also, sliding mode control (SMC) method has been praised by researchers recently for its diverse strengths, such as reliability, parameter variance robustness, fast dynamic response, and quick implementation, However, this method when applied to DC/DC converter has some weaknesses, including variation of the operating frequency at the control output (chattering phenomenon) [9]. Other optimization strategies have been implemented to various fields with the advancement of heuristic algorithms and artificial intelligence, which is the swarm intelligence algorithm added to MPPT [10]. This algorithm has powerful global search ability to track the MPP under single or variable irradiation conditions, but it is most likely to be premature at an early stage and it has a slow speed of convergence and search space is large.

Therefore, in addition to the above MPPT techniques, several papers were interested to the hybrid methods. Such methods involve the existing direct MPPT algorithms in conjunction with nonlinear controllers to solve their individual drawbacks. High speed and less oscillation in the MPPs is possible with these hybrid strategies. However, the reliability of this methods relies on the theory of the used regulator. In [11] , the P\&O algorithm is combined with integral sliding mode controller. This controller is performed through PWM-based control action which offers a fixed frequency operating. However, overshoot problem has been observed using this ISMC controller. [12] in this study, backstepping control combined with INC method is developed to improve the MPPT performances. This technique shows a minimum of error in the stable state, without satisfying the feature of robustness against the external disturbances.

In this paper a backstepping sliding mode control with integral action which is referred to us as backstepping integral sliding mode control (BISMC) has been proposed to improve chattering and steadystate error in tracking the MPP of a PV system when the environmental disturbances occur. This method is robust to environmental rapid changes and external disturbances. Integral control intervention is one of the main feedback control mechanisms. In a closed loop control system, it can remove steady state error.

The methodology for control proposed is constructed in two stages to control the PV system. The first stage consists of an ANN estimator for the reference voltage $\left(\mathrm{V}_{\text {ref }}\right)$. This last corresponds to the MPP voltage. The second is to perform the system tracking based on the developed BISMC regulator for a boost converter and according to the estimated voltage value. In this work, the proposed BISMC is used to constantly adjust the DC/DC boost converter duty cycle using the error between the PV model voltage and the MPP voltage estimated by the artificial neural network in order to remove this error.

To implement this control technique, a high gain observer has been constructed from the PV system based on dynamic equation, using the measured PV output voltage and current without measurement of DC converter states variables. This solution can reduce the PV system cost because it reduces the hardware sensor by software sensor (state observer) and reduces the sensors number.

Having regard to these ideas, the remain of this paper is described in the following way. The second section gives a configuration of the whole system overview. Sections three and four, present the system modelling. The MPPT proposal is presented in the fifth section with a detailed procedural design. The sixth part presents simulation results and discussions, which are followed up by conclusions in the final section.

\section{Proposed control methodology}

The working concept is unique for modern and proposed algorithms. The device proposed senses the temperature and incident irradiation on the PV module and provides this data for an off-line trained ANN block, as depicted in Fig. 1. The ANN generates the reference to generate an error signal that the backstepping integral sliding mode controller receives in comparison with the PV model voltage. The controller creates control input $\mu$ to control the width of the signal PWM and to force the converter to track the reference voltage. A new reference will be created for any temperature changes or energy lighting. However, a common reference value is produced by each collection of specific temperature and irradiation values. The PV unit running at this reference voltage thus guarantees that the system generates maximum power. 


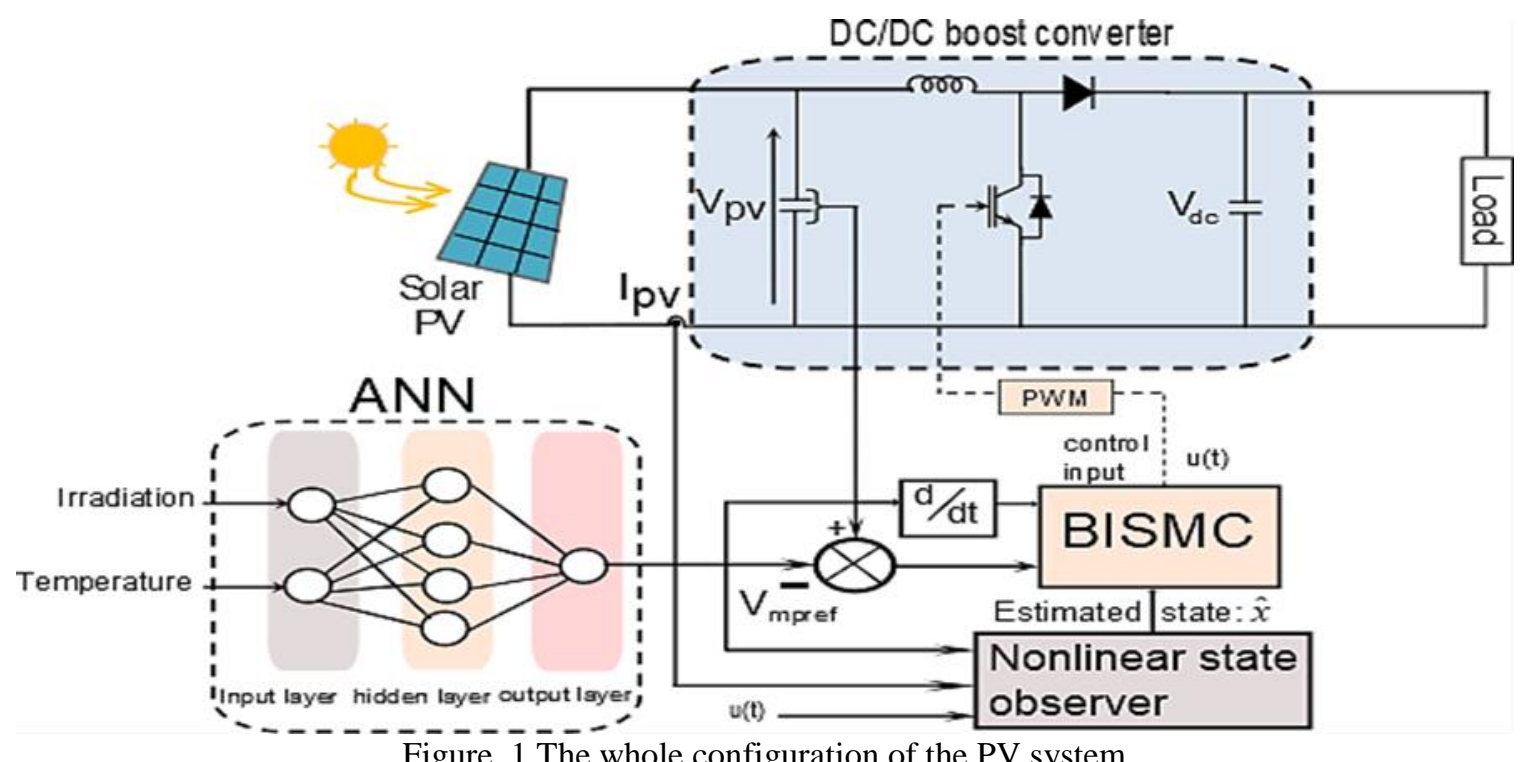

Figure. 1 The whole configuration of the PV system

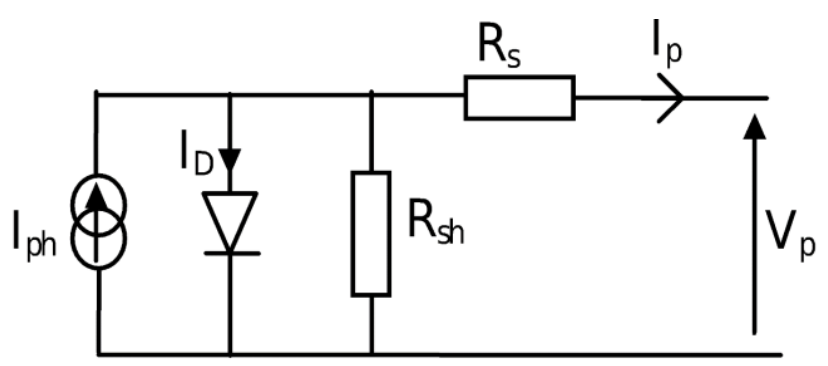

Figure. 2 The electric circuit of the PV cell

\section{Mathematic PV modelling:}

Fig. 2 illustrates the Photovoltaic generator (PVG) model used in this work, which consists of a photocurrent source and a diode connected with series and shunt resistances. In this work SM55 PV module is adopted to achieve a necessary voltage [13].The characteristic of the Photovoltaic generator can be presented by the following equations:

$$
\begin{gathered}
I_{p}=N_{p} I_{p h}-N_{p} I_{o}\left[\exp \left(\frac{q V_{p}}{n N_{s} K T}\right)-1\right] \\
I_{o}=I_{o r}\left(\frac{T}{T_{r}}\right)^{3} \exp \left(\frac{q E_{g}}{K \gamma}\left[\frac{1}{T_{r}}-\frac{1}{T}\right]\right) \\
I_{o r}=\frac{I_{s c r}}{\exp \left(\frac{q V_{o c}}{N_{s} K \gamma T}\right)-1} \\
I_{p h}=\left[I_{s c r} K_{i}\left(T-T_{r}\right)\right] \frac{E}{1000}
\end{gathered}
$$

Where:
Table 1. Main specifications of SM55 PV module

\begin{tabular}{|c|c|}
\hline Parameters & Values \\
\hline Rated power $(\mathrm{W})$ & 55 \\
\hline MPP Voltage, $(\mathrm{V})$ & 17.4 \\
\hline MPP Current $(\mathrm{A})$ & 3.15 \\
\hline Short-circuit current $(\mathrm{A})$ & 3.45 \\
\hline Open-circuit voltage $(\mathrm{V})$ & 21.7 \\
\hline$K_{i}(\mathrm{~A} / \mathrm{K})$ & $4 \times 10^{-4}$ \\
\hline $\mathrm{Ns}$ & 20 \\
\hline $\mathrm{Np}$ & 5 \\
\hline
\end{tabular}

$I_{p}[\mathrm{~A}], V_{p}[\mathrm{~V}]:$ the output current and the voltage of the PVG respectively.

$N_{p}, N_{s}$ : The parallel and the series connected cells respectively.

q: The charge of electron equals to $1.6 \times 10-19[\mathrm{C}]$.

$\mathrm{K}$ : The constant of Boltzmann equals to $1.3805 \times 10$ $23 \mathrm{~J} / \mathrm{K}$

$\gamma$ : The $\mathrm{p}-\mathrm{n}$ junction ideality factor.

$\mathrm{T}[\mathrm{K}]$ : The temperature of the cell.

$E_{g}$ : The energy used in the cell in the semiconductor range equals to $1.1[\mathrm{eV}]$

$T_{r}[\mathrm{~K}]$ : The nominal operating temperature of the cell.

$I_{o r}$ and $I_{o}$ : The saturation current of the cell at $T_{r}$ and The saturation current of the cell respectively.

$I_{\text {scr }}[\mathrm{A}]$ : The short-circuit current of the cell.

$K_{i}[\mathrm{~A} / \mathrm{K}]$ : The coefficient of the temperature of shortcircuit current.

$\mathrm{E}[\mathrm{W} / \mathrm{m} 2]$ : The sun radiation.

For distinct sun radiations $\mathrm{E}$ and temperatures $\mathrm{T}$ values the I-V and V-P features of PVG are shown in 


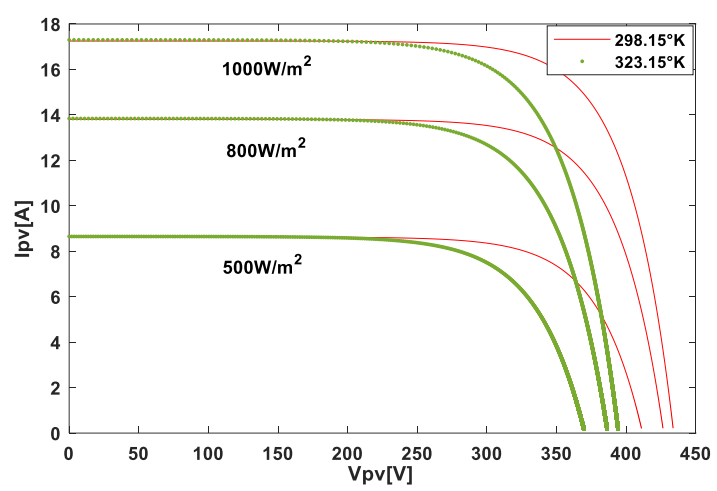

Figure. $3 \mathrm{Vpv}$ - Ipv at various sun-lights and cell temperatures

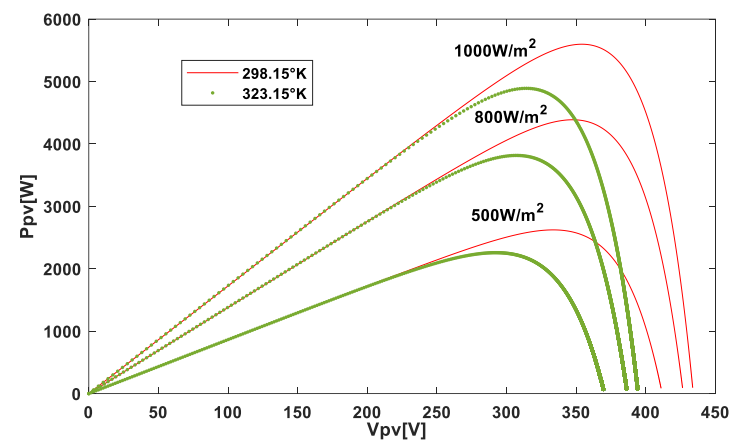

Figure. $4 \mathrm{Ppv}$ - Vpv at various sunlights and cell temperatures

Figs. 3 and 4. These figures show that the atmospheric situation has an important impact on maximum power. When solar radiation is continuous, the strength of the PVG reduces with growing temperature. The increase in cell temperature decreases the open circuit voltage linearly and rises the current slightly. PVG energy is reduced as solar irradiation drops at a steady cell temperature. When the sunlight decreases slowly the short-circuit current increases and the open circuit voltage decreases.

\section{DC/DC boost converter modelling:}

The basic circuit diagram of the step-up converter is shown in Fig. 1. The boost converter is an adaptation stage between the PVG and the load. It is used to control the PVG output voltage and hence to extract the maximum power acting on the duty cycle.

Based on the state averaging method [14], the switched model can be redefined by the average PWM model as follow:

$$
\left\{\begin{array}{c}
\frac{d V_{p v}}{d t}=\frac{1}{C_{p v}}\left(I_{p v}-I_{L}\right) \\
\frac{d I_{L}}{d t}=\frac{1}{L}\left(V_{p v}-(1-u) V_{d c}\right) \\
\frac{d V_{d c}}{d t}=\frac{1}{C_{d c}}\left(-I_{d c}+(1-u) I_{L}\right)
\end{array}\right.
$$

Where $V_{p v}, I_{L}$ and $V_{d c}$ are the PVG output voltage, the inductor current and the converter output voltage respectively; $\mathrm{u}$ is the duty ratio; and $I_{p v}$ means the average state of output current of the PVG. This averaged state space model is then used to design the proposed controller.

\section{The proposed controller for MPPT}

\subsection{Artificial neural network}

Artificial neural networks are a way of coping with non-linear problems. They learn from examples and process incomplete information. They perform fast prediction once they are trained. The ANN can essentially be represented by a directed graph in which the nodes and the edges are the neurons and the synapses respectively. Two main types of ANN structure emerge from the way the neurons are related to one another: Feed-forward neural network (FNN) and recurrent neural network (RNN). In this work, the feed-forward neural network is considered, Where the input layer neurons serve only as buffers for the transmission of the input signals (solar irradiation, temperature). The output layer has one neuron which provides the VMPP voltage value corresponding to the maximum power point. The input variables, which are the irradiance and the temperature, are transmitted to the hidden layer through the two neurons of the input layer. The hidden layer is composed of five neurons whose activation function is sigmoid function which is given by:

$$
f_{h}(u)=\frac{1}{1+e^{-u}}
$$

Therefore, the output activation of neurons in the hidden layer is determined using the following relation [15]:

$$
x=f_{h} \sum w_{h}[G T]^{T}+b_{h}
$$

The neurons strengths respectively of the hidden, output layer are represented by the weight matrix denoted respectively by $w_{h}, w_{o}$ and the biases vector denoted respectively by $b_{h}, b_{o}$. The input signals vector contains the irradiation $G$ and temperature $T$. The output layer has one neuron whose linear activation function as follows: 


$$
f_{o}(x)=x
$$

This neuron provides the computed MPP voltage using the following relationship:

$$
\widehat{V}_{m p p}=f_{o}\left(w_{o} x+b_{o}\right)
$$

The neural network database should include a broad variety of measures to enhance the predictive precision. The database used in this work is established from the simulation of PV module. Fig. 5 represents the database that is used to train the ANN. This database contains the patterns of irradiation, temperature and the corresponding MPP voltage.

The ANN was trained off-line with the Bayesian regularization optimization technique using the Back-Propagation algorithm (BP), That is the most commonly employed supervised method for FNN to minimize the mean squared error (MSE) and it proves good performance and computing efficiency. The MSE is calculated as follow:

$$
M S E=\frac{1}{n} \sum_{i=1}^{n}\left(V_{m p}(i)-\widehat{V}_{m p}(i)\right)^{2}
$$

Where $V_{m p}$ is the $\widehat{V}_{m p}$ ith target and is its estimated output. Figs. 6 and 7 demonstrate respectively the development of the error of performance for the ANN based MPPT approach and a comparison between the ANN calculated outputs and the targets.

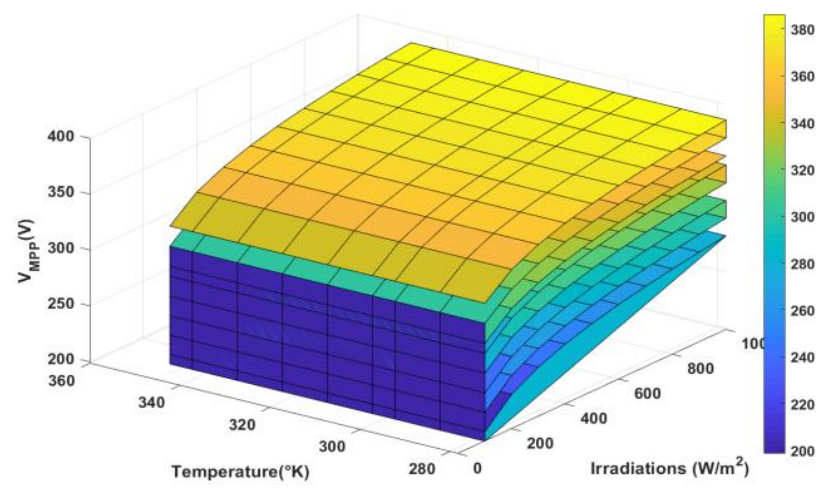

Figure. 5 The optimal PV voltage according to the environmental conditions changes

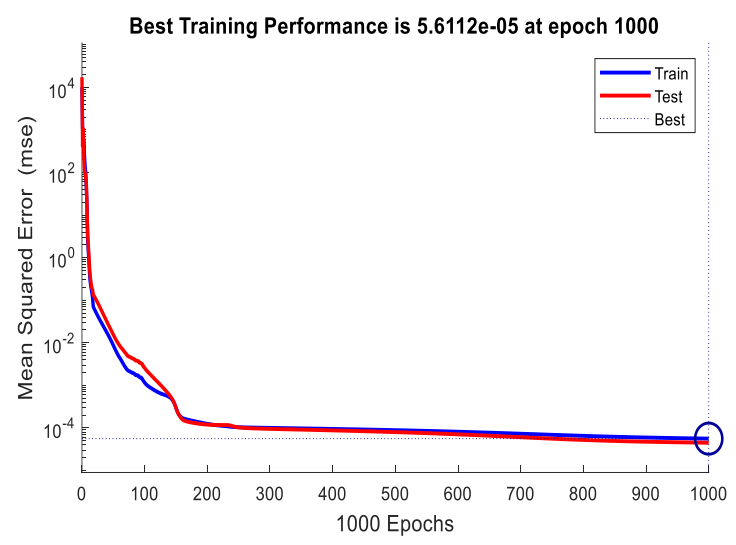

Figure. 6 The MSE evolution during training
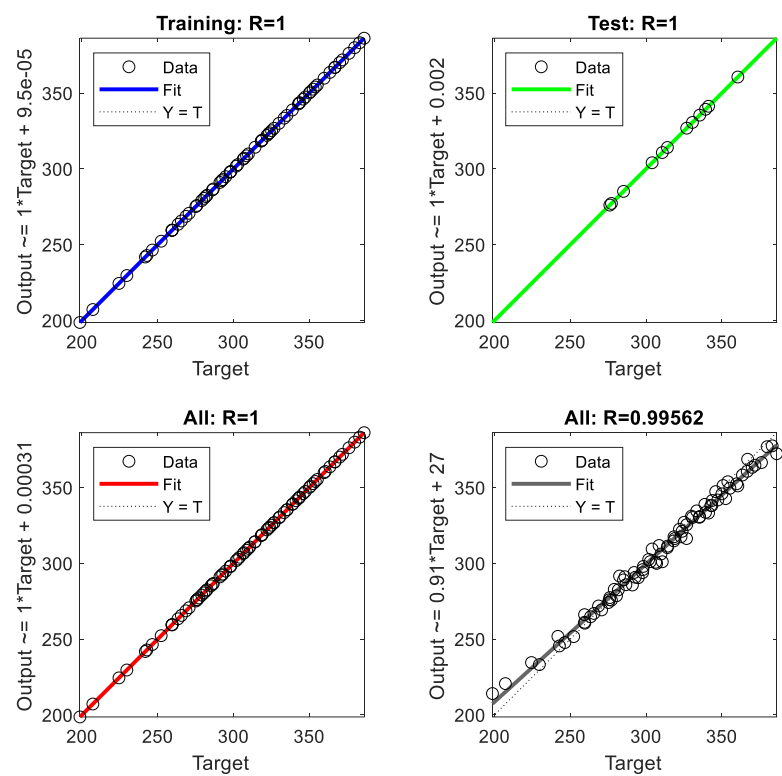

Figure. 7 The ANN predicted outputs and targets during the learning stage

Following the training phase, the ANN-based MPPT controller should provide MPP voltage in all weathers. One advantage of this controller is that a large number of iterations are not necessary to find the MPP, thus reducing oscillation around the MP and increasing efficiency.

\subsection{The backstepping integral sliding mode controller}

Following the brief introduction of conventional SMC, the proposed BISMC is introduced in this Section. The SMC is a tool for controlling non-linear dynamic systems that is efficient and strong based on discontinuous control laws [16] .The SMC regulation law includes an equivalent control $u_{e q}(t)$ and discontinuous control law $u_{d}(t)$ :

$$
u(t)=u_{d}(t)+u_{e q}(t)
$$


The following is the selection for a sliding surface to create an SMC for the PV system scheme:

$$
\sigma=K_{1} e(t)+\dot{e}(t), K_{1}>0
$$

Using the tracking error:

$$
e=V_{p v}-V_{r e f}
$$

Let us then develop the corresponding control by placing the sliding surface time derivative at zero:

$$
\begin{gathered}
u_{e q}=\frac{L C_{p v}}{V_{0}}\left[K_{1} \dot{e}+\frac{1}{C_{p v}} \dot{I}_{p v}+\frac{1}{L C_{p v}}\left(V_{d c}\right.\right. \\
\left.\left.-V_{p v}\right)-\ddot{V}_{r e f}\right]
\end{gathered}
$$

Find candidate a Lyapunov function to develop a discontinuous control law:

$$
v(\sigma)=\frac{1}{2} \sigma^{2}(t) \geq 0
$$

The time derivative of $v(\sigma(t))$ along the dynamic system trajectories in Eq. (5) and the sliding surface in Eq. (11) is:

$$
\begin{aligned}
\dot{V}(\sigma(t)) & =\sigma(t) \dot{\sigma}(t) \\
=\sigma(t) & {\left[k_{1} \dot{e}(t) \frac{1}{C_{p v}} \dot{I}_{p v}+\frac{1}{L C_{p v}}\left(V_{d c}-V_{p v}\right)\right.} \\
& \left.-\frac{V_{d c}}{L C_{p v}}\left(u_{e q}+u_{d}\right)-\ddot{V}_{r e f}\right]
\end{aligned}
$$

Substituting Eq. (13) into Eq. (15), it gives:

$$
\begin{aligned}
\dot{V}(\sigma(t))= & \sigma(t)\left[\frac{V_{d c}}{L C_{p v}} u_{d}\right] \\
& \leq-K \sigma(t) \operatorname{sign}(\sigma(t)) \\
= & -K \sigma(t) \leq 0
\end{aligned}
$$

With the continuous control law:

$$
u_{d}(t)=-\frac{L C_{p v}}{V_{d c}} \operatorname{sign}(\sigma(t))
$$

Where K should be positive, and

$$
\operatorname{sign}(\sigma(t))=\left\{\begin{array}{l}
1, \sigma(t)>0 \\
0, \sigma(t)=0 \\
1, \sigma(t)<0
\end{array}\right.
$$

The track of the dynamic system of the closed loop therefore ends in a certain time on the sliding surface and is retained because $\dot{V}(\sigma(t))=$ $-K|\sigma(t)| \leq 0$ The chattering phenomenon from the imperfections of switching devices is the main drawbacks of the SMC. Varied approaches using the hyperbolic function instead of signum function to reduce this chattering. Hence, the discontinuous control law becomes:

$$
u_{d}(t)=-\frac{L C_{p v}}{V_{d c}} \tanh (\sigma(t))
$$

To address a few inconveniences of conventional SMC, which have been built above, such as chattering or steady state error and tracking error, the BISMC is proposed. The following are step by step concept procedures. Considering again the system dynamic state variables of the boost converter given in Eq. (5) and the tracking error in Eq. (12). its time derivation yields following equation:

$$
\begin{aligned}
\dot{e}= & \dot{V}_{p v}-\dot{V}_{r e f} \\
& =\left[\frac{i_{p v}}{C_{p v}}-\frac{i_{L}}{C_{p v}}\right]-\dot{V}_{r e f}
\end{aligned}
$$

In order to check the convergence of e to zero, a positive definite Lyapunov function $V_{0}$ is considered:

$$
V_{0}=\frac{1}{2} e^{2}
$$

Its time derivative along the solution of (19) is specified by:

$$
\dot{V}_{0}=\mathrm{e} \dot{e}=e\left[\frac{1}{C_{p v}}\left(i_{p v}-i_{L}\right)-\dot{V}_{r e f}\right]
$$

When $i_{L}$ state is considered as a virtual input in Eq. (3). $i_{L}=\delta_{0}(e)=i_{p v}+C_{p v}\left[C_{1} e-\dot{V}_{r e f}\right]$, the origin of $\dot{e}=-C_{1} e$ is globally asymptotically stable since $\dot{V}_{0}=-C_{1} e<0$ for $C_{1}>0$.

To develop a feedback control law by incorporating an integral measurement which helps monitor accuracy for parametric insecurity and robustness in high-frequency unmodeled dynamics, the virtual control is turned to:

$$
\begin{array}{r}
i_{L}=\delta(e)=i_{p v}+C_{p v}\left[C_{1} e+\right. \\
\left.C_{2} \int_{0}^{t} e d \tau-\dot{V}_{r e f}\right]
\end{array}
$$


Where $C_{2}>0$, substituting Eq. (22) into Eq. (19), one has:

$$
\dot{e}=-C_{1} e-C_{2} \int e d \tau
$$

The function of Lyapunov in (20) can be modified with the integral action.

$$
V_{1}=\frac{1}{2} e^{2}+\frac{1}{2} C_{2}\left(\int_{0}^{t} e d \tau\right)^{2}>0, \forall e \neq 0
$$

The time-related derivation of the above equation is:

$$
\dot{V}_{1}=\mathrm{e} \dot{e}+C_{2} e \int_{0}^{t} e d \tau
$$

The outcomes of Eq. (23) replacement with Eq. (25)

$$
\dot{V}_{1}=-C_{2} e^{2} \leq 0
$$

In the first step the scheme with the integral action is therefore asymptotically stable.

$$
\begin{gathered}
\sigma=i_{L}-\delta(e) \\
=i_{L}-i_{p v}-C_{p v}\left[C_{1} e+C_{2} \int_{0}^{t} e d \tau\right. \\
\left.-\dot{V}_{\text {ref }}\right]
\end{gathered}
$$

The controlled system may be converted into the form below:

$$
\dot{e}=\sigma-C_{1} e-C_{2} \int_{0}^{t} e d \tau
$$

Let us identify the sliding surface with the help of the backstepping model and the SMC using Eq. (24):

$$
\sigma=\dot{e}+C_{1} e+C_{2} \int_{0}^{t} e d \tau
$$

A necessary and sufficient condition for the tracking error to stay on the sliding surface is $\dot{\sigma}(t)=$ 0

$$
\dot{\sigma}=\ddot{e}+C_{1} \dot{e}+C_{2} e=0
$$

The following composite Lyapunov function is supposed to provide stability of the suggested BISMC:

$$
V_{2}=V_{1}+\frac{1}{2}(\sigma)^{2}>0, \forall e \neq 0
$$

The Lyapunov derivative function according to alternatives 2 and 6 is:

$$
\begin{aligned}
\dot{V}_{2}= & e\left(\sigma-C_{1} e-C_{2} \int_{0}^{t} e d \tau\right)+ \\
& C_{2} e \int_{0}^{t} e d \tau+\sigma \dot{\sigma} \\
= & -C_{1} e^{2}+\sigma+\sigma\left[\frac { 1 } { L } \left(V_{p v}-V_{0}(1-\right.\right. \\
& u))-\dot{I}_{p v}-C_{1} C_{p v} \dot{e}- \\
& \left.C_{2} C_{p v} e+C_{p v} \ddot{V}_{r e f}\right] \\
=- & C_{1} e^{2}+\sigma\left[\left(1-C_{2} C_{p v}\right) e-C_{1} C_{p v} \dot{e}-\dot{I}_{p v}+\right. \\
\frac{1}{L}\left(V_{p v}-\right. & \left.\left.V_{d c}(1-u)\right)+C_{p v} \ddot{V}_{r e f}\right]
\end{aligned}
$$

The term between brackets multiplying by $\sigma$ is set to $-C_{3} \sigma$ for $C_{3}>0$, in order to make $\dot{V}_{2}(e)$ negative definite. The time derivative of the function Lyapunov is therefore definitely negative:

$$
\dot{V}_{2}=-C_{1} e^{2}-C_{3} \sigma^{2}
$$

In order to develop the feedback control statute to ensure the stability of the whole scheme, let us select a discontinuous control:

$$
u_{d}=-\frac{L}{V_{d c}} \Gamma \tan (\sigma)
$$

And the equivalent control is:

$$
\begin{aligned}
& u_{e q}=\frac{L}{V_{d c}}\left[C_{1} C_{p v} \dot{e}+\dot{I}_{p v}-(1-\right. \\
& \left.\left.C_{2} C_{p v}\right) e-\frac{V_{p v}}{L}+\frac{V_{0}}{L}-C_{p v} \ddot{V}_{r e f}-C_{3} \sigma\right]
\end{aligned}
$$

With the help of the control laws Eqs. (34) and (35), the stability proof of PV system controlled by the BISMC can be made as follows:

$$
\dot{V}_{2}=-C_{1} e^{2}-C_{3} \sigma^{2}-\Gamma|\sigma(t)| \leq 0
$$

The above analysis shows that the conditions of achievement are guaranteed for $\Gamma \geq 0$.

Putting Eqs. (34) and (35) together and including Eq. (29), the feedback control law can be rewritten as follows:

$$
\begin{array}{r}
u=\frac{L}{V_{d c}}\left[\left(C_{1} C_{p v}-C_{3}\right) \dot{e}+\dot{I}_{p v}-(1-\right. \\
\left.C_{2} C_{p v}+C_{1} C_{3}\right) e-\frac{1}{L}\left(V_{p v}-V_{d c}\right)- \\
\left.C_{p v} \ddot{V}_{r e f}-C_{3} C_{2} \int e d \tau-\Gamma \tanh (\sigma)\right]
\end{array}
$$


Tanh function is used for the discontinuous control law $u_{d}$ in Eq. (34) instead of sign function in order to reduce the chattering phenomenon.

\subsection{The high gain observer}

In practice the full states variables of the system are rarely available for the feedback. To solve this problem, a high gain observer is suggested. Also, it is proposed to replace certain sensors, which reduces the cost and space. This observer needs only the PV voltage and the PV current measurement to estimate the boost output voltage and the inductor current.

The dynamic model of the PV system can be written under the following canonical form:

$$
\left\{\begin{array}{c}
\dot{x}_{1}=a_{1}(u) x_{2}+\varphi_{1}\left(x_{1}, u\right) \\
\dot{x}_{2}=a_{2}(u) x_{3}+\varphi_{2}\left(x_{2}, u\right) \\
\dot{x}_{3}=\varphi_{3}\left(x_{3}, u\right) \\
y=x_{1}
\end{array}\right.
$$

Using Eqs. (5) and (36), it can be concluded that:

$$
\begin{aligned}
& \qquad\left\{\begin{array}{c}
a_{1}=-1 / C_{p v} \\
a_{2}=(1-u) / L
\end{array}\right. \\
& \text { And } \\
& \qquad \begin{array}{c}
\varphi_{1}=\frac{1}{C_{p v}} I_{p v} \\
\varphi_{2}=\frac{1}{L} V_{p v} \\
\varphi_{3}=-\frac{1}{C_{d c}}\left[\frac{1}{R} V_{d c}-(1-u) I_{L}\right]
\end{array}
\end{aligned}
$$

The PV system (5) can be represented in a general observable canonical form given by:

$$
\dot{x}=A(u) x+\varphi(x, u)
$$

Where:

$A=\left(\begin{array}{ccc}0 & a_{1} & 0 \\ 0 & 0 & a_{2} \\ 0 & 0 & 0\end{array}\right) ; C=\left[\begin{array}{lll}1 & 0 & 0\end{array}\right] ; \varphi=\left[\begin{array}{lll}\varphi_{1} & \varphi_{2} & \varphi_{3}\end{array}\right]^{T}$

Assuming $\varphi(x, u)$ is the locally Lipchitz nonlinear function with respect to $\mathrm{x}$ uniformly to $\mathrm{u}$.

A candidate observer for the PV system is described as follows:

$$
\left\{\begin{array}{c}
\dot{\hat{x}}=A(u) \hat{x}+\varphi(\hat{x}, u)-S^{-1} C^{T}(C \hat{x}-y) \\
\dot{S}=-\theta S-A^{T}(u)-S A(u)+C^{T} C \\
\hat{y}=c \hat{x}
\end{array}\right.
$$

Where $\hat{x}$ is the estimation of the full state vector, $\mathrm{y}$ is the measured output, $u$ is the control input of the PV system, $\mathrm{S}$ is a symmetric positive definite matrix and a solution of the differential Lyapunov equation. $\theta$ is the observer adjustment positive parameter.

\section{Simulation results and discussion}

The general structure of the PV system, depicted in Fig. 1, which consists of a PV module, a boost converter connected to the proposed MPPT controller and feeding a resistive load. It is constructed here with $\mathrm{L}=1.5 \mathrm{mH}, \mathrm{C}_{\mathrm{pv}}=470 \mu \mathrm{F}, \mathrm{C}_{\mathrm{dc}}=4700 \mu \mathrm{F}$, and $\mathrm{R}=50 \Omega$. The specifications of the adopted SM55 PV module, with 20 and 5 modules connected in series and parallel respectively, are given in Table 1 . The controller parameters are as follow: $\mathrm{C}_{1}=30 \times 10^{2}$; $\mathrm{C}_{2}=100 ; \mathrm{C}_{3}=300 ; \Gamma=10^{6}$.

In order to investigate the controller effectiveness, simulations are carried out under Matlab/Simulink. The scheme under study is evaluated for rapid modifications in sunlight and temperature, as depicted in Fig. 8.

The system control/observer robustness is evaluated with this change of the environmental conditions. From Figs. 9, 10, and 11, it is clearly obvious that the real states of PV system converge to their estimates.

Fig. 12 depicts the power reached by the proposed controller. It is clear from this figures that this controller works properly with good tracking performances against the environmental changes.
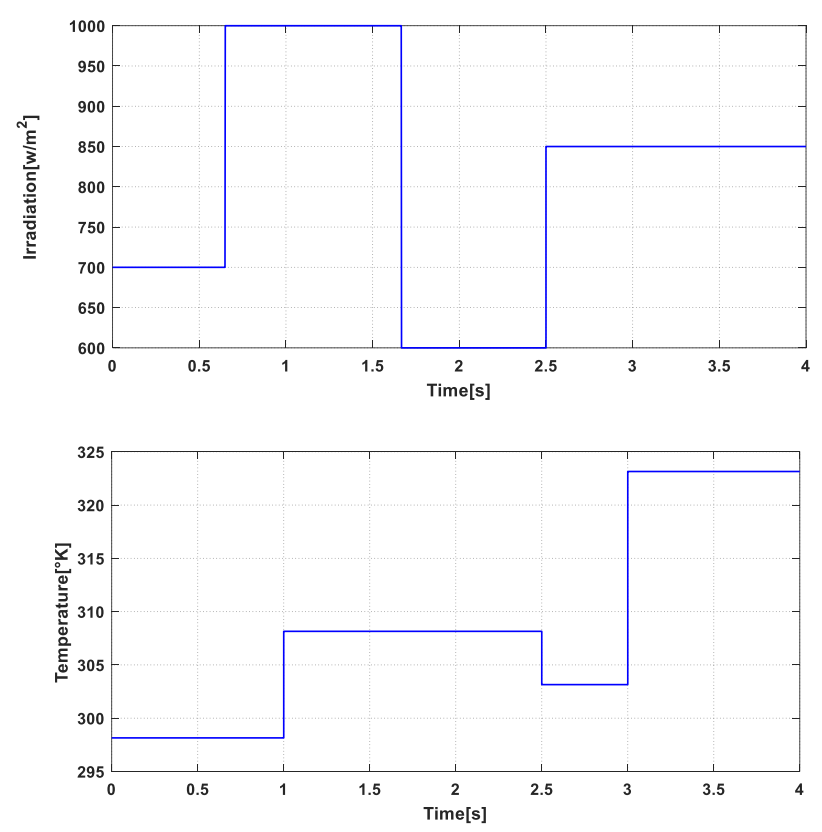

Figure. 8 The irradiation and temperature changes 


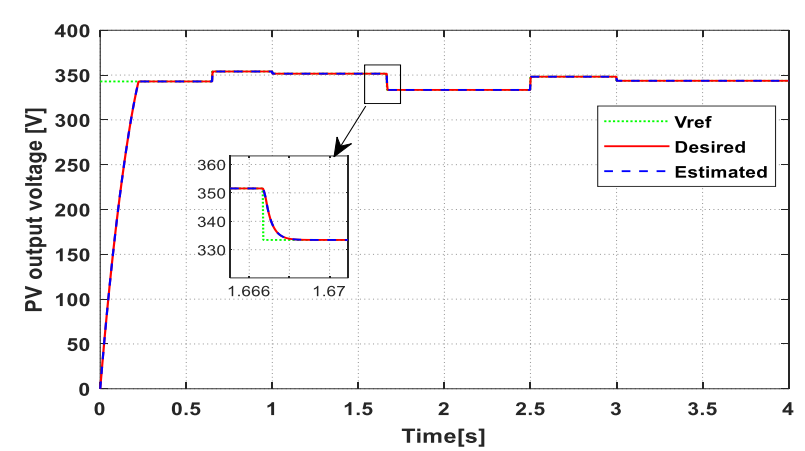

Figure. 9 The PV output voltage of the proposed controller with its estimated value

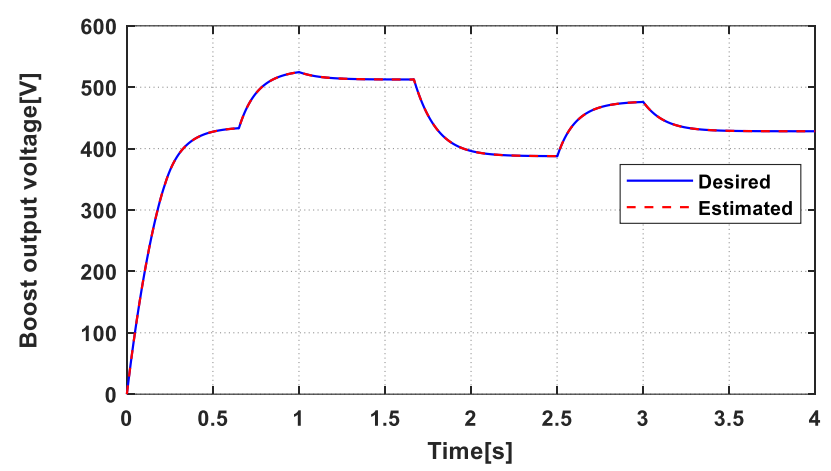

Figure. 10 The boot output voltage with its estimated value

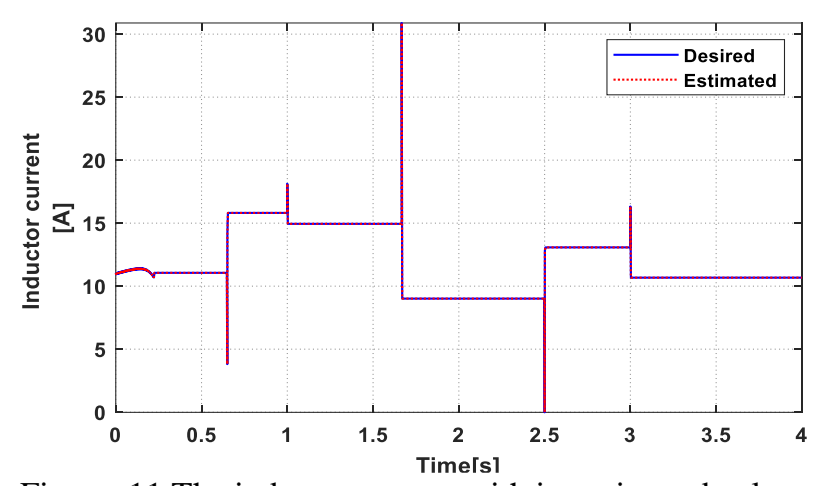

Figure. 11 The inductor current with its estimated value

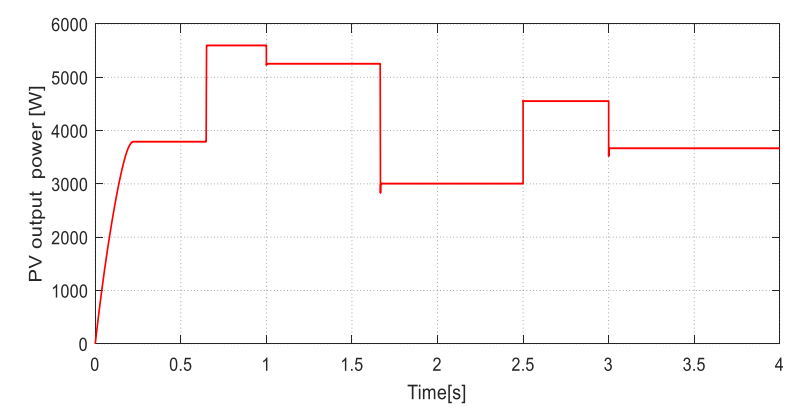

Figure. 12 The PV output power of the proposed controller

In order to more evaluate the performances of the proposed controller. It is compared with the standard SMC controller. The PV output voltage, the PV output power are depicted in Figs. 13 and 14. The performance of the proposed BISMC according to rise time and settling time is much better than of the traditional SMC. As seen in Fig. 13, the BISMC is two times faster than the other in response. The settling time for the BISMC is approximately $0.23 \mathrm{~s}$ but that for the SMC is about 0.35s. Almost no overshoot is observed for both controllers. As can be observed from Fig. 13 the undesirable high frequency chattering is significantly reduced by BISMC. It is clearly obvious from Fig. 14 that the BISMC is rapidly reached the maximum power compared to SMC. Both the tracking errors for both controllers converge to zero but in the environmental changes the tracking error of the SMC controller takes more time to converge, as can be observed in Fig. 15. Figs. 16 and 17 illustrate the sliding surface and the duty cycle comparison. It is clearly obvious from these results that the BISMC has higher accuracy and reliability in tracking the maximum power point in different solar irradiations and cell temperatures.

To prove more the proposed controller effectiveness under the environmental condition changes, this controller is compared with the twostage methods which are the backstepping combined with the P\&O and the PSO algorithms, presented respectively in $[17,18]$. These results are displayed in Figs. 18 and 19.

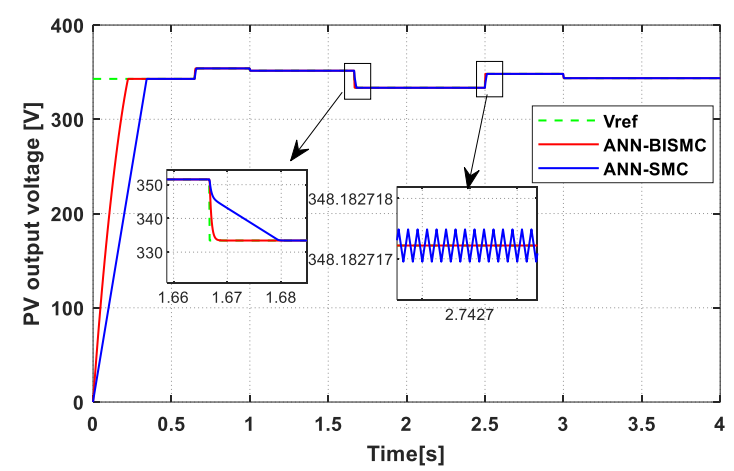

Figure. 13 PV output voltage of the proposed controller and the standard sliding mode controller

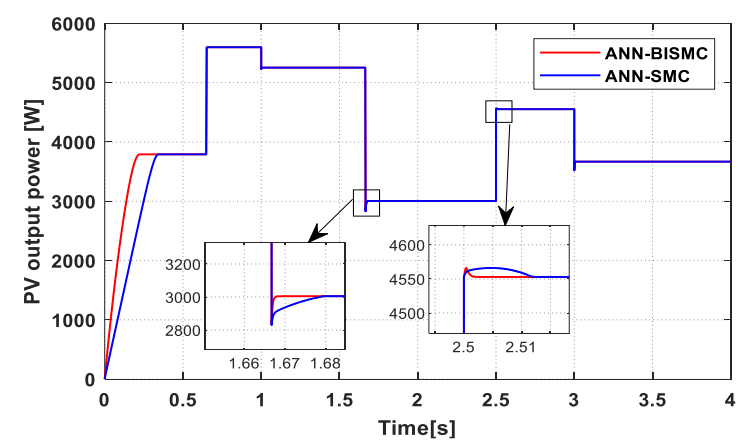

Figure. 14 PV output power of the proposed controller and the standard sliding mode controller 


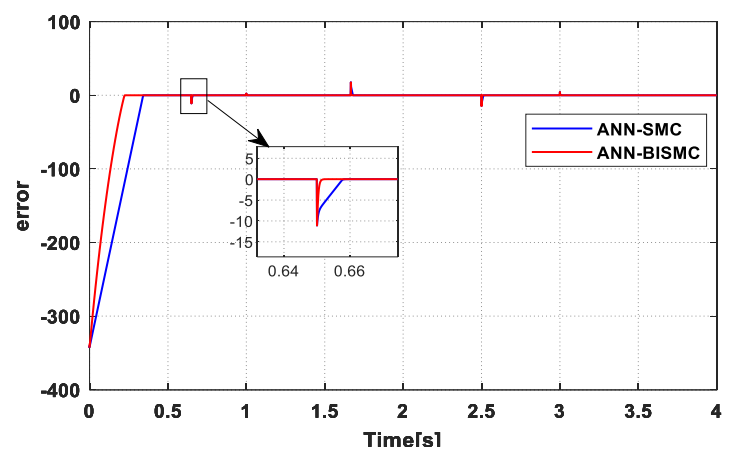

Figure. 15 The tracking errors of the proposed controller and the standard sliding mode controller

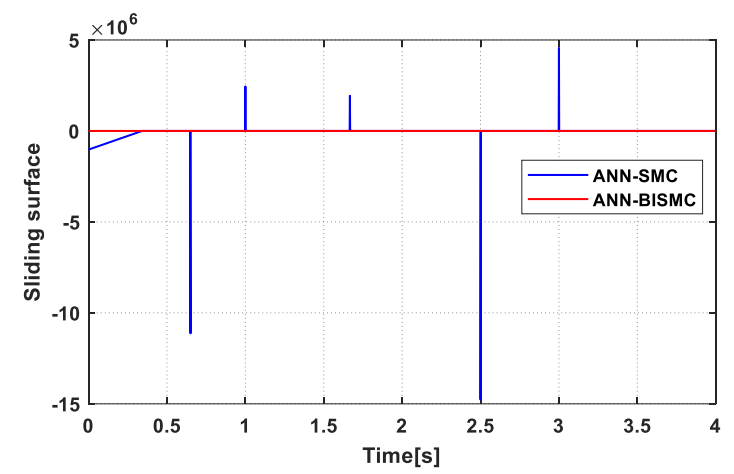

Figure. 16 The sliding surfaces of the proposed controller and the standard sliding mode controller

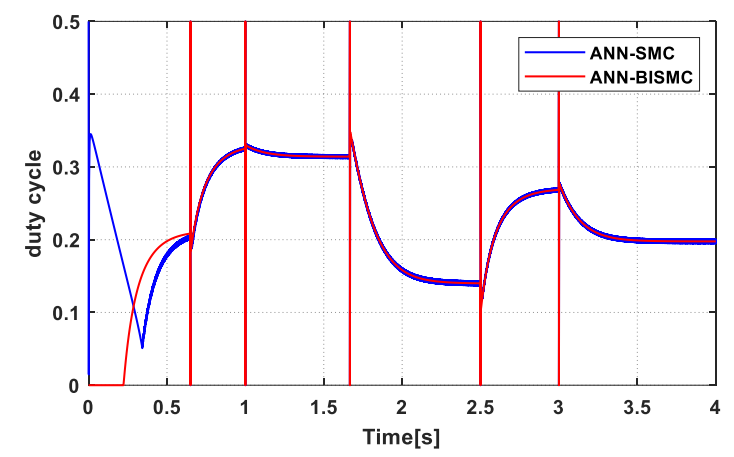

Figure. 17 The duty cycle of the proposed controller and the standard sliding mode controller

Fig. 18 depicts the PV output voltage by using the comparative study between the proposed method, PSO-backstepping and P\&O-backstepping. As this figure illustrates, the proposed controller can scan and track precisely the reference voltage without steady state error or any overshoot during the changes of irradiation and temperature.

Also, as can be observed from Fig. 19, the ANN$\mathrm{BISMC}$ can reach the maximum power more rapidly without any oscillation around the MPP compared to the other methods that makes more iterations to find and track the global maximum power points of power, which makes the system slow.

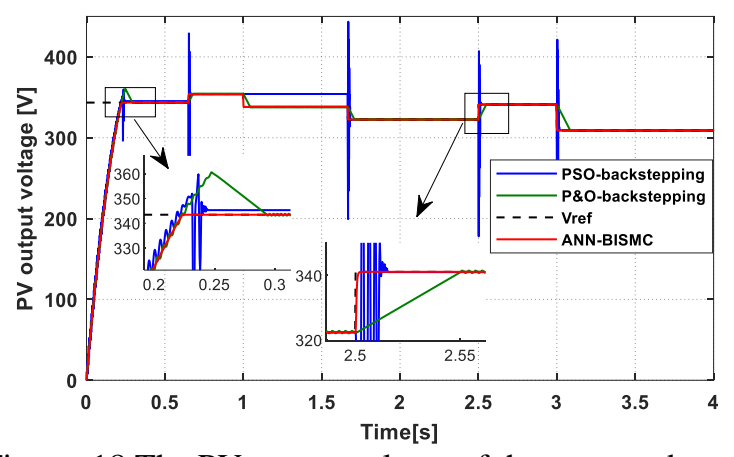

Figure. 18 The PV output voltage of the proposed method compared to the P\&O-Backstepping and PSO-

Backstepping

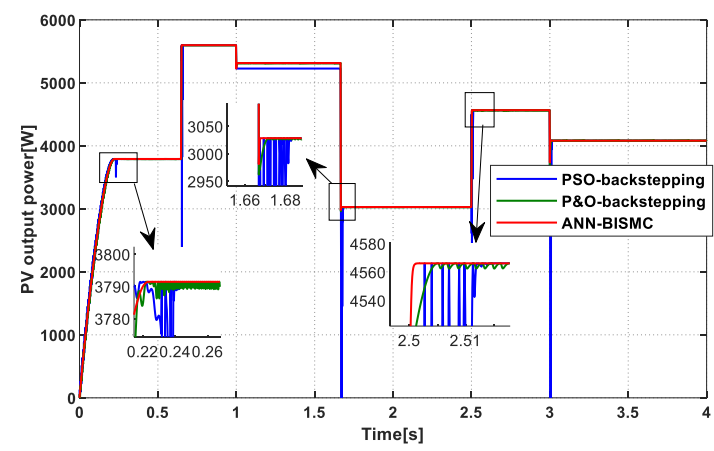

Figure. 19 The PV output power of the proposed method compared to the P\&O-Backstepping and PSO-

Backstepping

\section{Conclusion}

In this study, the BISMC combined with the ANN for PV system is suggested in order to overcome the difficulties in environmental conditions changes. The stability analysis of the control system based on Lyapunov method is presented. simulation results are carried out under Matlab/Simulink. In order to confirm the effectiveness of the proposed controller comparisons with the ANN-SMC, P\&Obackstepping and PSO-backstepping for output PV voltage and tracking the maximum power are introduced. Along with the simulation results, the proposed BISMC makes an improvement in steadystate error without voltage fluctuation (ripples). Furthermore, the overshoot is eliminated, the tracking time is reduced and tracking efficiency is improved, it takes only about $1 \mathrm{~ms}$ to track the reference maximum power voltage while the other methods takes more tracking time. The proposed BISMC provides not only a faster transient response but also a smaller steady state error with $98 \%$ of efficiency. Also, the proposed BISMC decreases chattering on the control signal and at the same time, it improves robustness against the environmental changes. 
Moreover, this controller is combined with the high-gain observer in order to minimize number of sensors required. From the simulation results, the high-gain observer proves its ability to replace some sensors of the voltage and the current.

The proposed controller will be implemented in real-time using an external card in order to validate its effectiveness tracking the MPP under the environmental condition changes.

\section{Conflicts of Interest}

The authors declare no conflict of interest.

\section{Author Contributions}

Rafika El Idrissi, as the corresponding author, has designed the proposed controller method for MPPT. Also, she has modelled the proposed system using Matlab/Simulink environment. Ahmad Abbou has supervised the written paper and providing the necessary data. Mohcine Mokhlis has contributed to the writing and the paper organization. All authors approved the final version.

\section{References}

[1] F. Zaouche, D. Rekioua, J. P. Gaubert, and Z. Mokrani, "Supervision and control strategy for photovoltaic generators with battery storage", International Journal of Hydrogen Energy, Vol. 42, No. 30, pp. 19536-19555, 2017.

[2] A. Mohapatra, B. Nayak, P. Das, and K. B. Mohanty, "A review on MPPT techniques of PV system under partial shading condition", Renewable and Sustainable Energy Reviews, Vol. 80, pp. 854-867, 2017.

[3] J. Ahmed and Z.Salam, "An improved perturb and observe $(\mathrm{P} \& \mathrm{O})$ maximum power point tracking (MPPT) algorithm for higher efficiency", Applied Energy, Vol. 150, pp. 97108, 2015.

[4] M. Rezkallah, A. Hamadi, A. Chandra, B. Singh, and A. Hamadi, "Design and Implementation of Active Power Control With Improved P\&O Method for Wind-PV-BatteryBased Standalone Generation System", IEEE Transactions on Industrial Electronics, Vol. 65, No. 7, pp. 5590-5600, 2018.
[5] Q. Mei, M. S. Shan, L. Liu and J. M. Guerrero, "A novel improved variable step-size incremental-resistance MPPT method for PV systems", IEEE Transactions on Industrial Electronics, Vol. 58, No. 6, pp. 2427-2434, 2011.

[6] U. Yilmaza, A. Kircay, and S. Borekci, "PV system fuzzy logic MPPT method and PI control as a charge controller", Renewable and Sustainable Energy Reviews, Vol. 81, pp. 9941001, 2018.

[7] R. Divyasharon, R. N. Banu and D. Devaraj, "Artificial Neural Network based MPPT with CUK Converter Topology for PV Systems Under Varying Climatic Conditions", In: Proc. of the IEEE International Conf. on Intelligent Techniques in Control, Optimization and Signal Processing (INCOS), pp.1-6, 2019.

[8] L. M.E lobaid, A. K. Abdelsalam, and E. E. Zakzouk, "Artificial neural network-based photovoltaic maximum power point tracking techniques: A survey", IET Renewable Power Generation, Vol. 9, No. 8, pp. 1043-1063, 2015.

[9] P. A. O. Valencia and C. A. Ramos-Paja, "Sliding-mode controller for maximum power point tracking in grid-connected photovoltaic systems", Energies, Vol. 8, No. 11, pp. 1236312387, 2015.

[10] T. Wei, D. Liu, and C. Zhang, "An Improved Particle Swarm Optimization (PSO)-Based MPPT Strategy for PV System", MATEC Web of Conferences, Vol. 139, 2017.

[11] A. Kihal, F. Krim, and A. Laib, "MPPT voltage oriented loop based on integral sliding mode control applied to the boost converter", In: Proc. of the 6th International Conf. on Systems and Control (ICSC), pp.205-209, 2017.

[12] A. Taouni, A. Abbou, M. Akherraz, A. Ouchatti, and R. Majdoul, "MPPT design for photovoltaic system using backstepping control with boost converter", In: Proc. International Renewable and Sustainable Energy Conference (IRSEC, Marrakech, Morocco, ), pp. 469-475, 2016. 
[13] M. Mokhlis, M. Ferfra, and R. Elidrissi, "High Gain Observer-Based Control for GridConnected PV System Under", International Journal of Intelligent Engineering \& Systems, Vol. 13, No. 2, pp. 161-172, 2019.

[14] R. Elidrissi, A. Abbou, and M. Salimi, "Artificial Neural-Network-Based Maximum Power Point Tracking for Photovoltaic Pumping System Using Backstepping Controller", In: Proc. of the 59th International Scientific Conf. on Power and Electrical Engineering of Riga Technical University (RTUCON), Riga, Latvia, 2018.

[15] M. Kermadi and E. M. Berkouk, "Artificial intelligence-based maximum power point tracking controllers for Photovoltaic systems: Comparative study", Renewable and Sustainable Energy Reviews, Vol. 69, pp. 369386, 2017.

[16] A. C. Cheickne, M. Cherkaoui, and M. Mokhlis, "MPPT Control for Photovoltaic System using hybrid method under variant weather condition", In: Proc. of International Conf. on Wireless Technologies, Embedded and Intelligent Systems (WITS), Fez, Morocco, 2019.

[17] R. Elidrissi, A. Abbou, S. Rhaili, and M. Salimi, "Maximum Power Point Tracking of Photovoltaic Systems using Backstepping Controller", In: Proc. of International Conf. on Engineering and Technology, ICET, Antalya,Turkey, 2017.

[18] M. Mokhlis, M. Ferfra, and R. Elidrissi, "High Gain Observer-Based Control for GridConnected PV System Under Partial Shading Effect", International Journal of Intelligent Engineering and Systems, Vol. 13, No. 2, pp. 161-172, 2020. 